\title{
PENGGUNAAN DC-AC CONVERTER SEBAGAI ALTERNATIF PENGGANTI GENSET UNTUK MENSUPLAI BEBAN LISTRIK SAAT TERJADI PEMADAMAN LISTRIK
}

\author{
Antoni Simanjuntak ${ }^{1}$, Jandri Louhenapessy ${ }^{2}$ \\ E-mail: 1antoni_s15@yahoo.com, 2jandrileonora@yahoo.co.id \\ 1,2Jurusan Teknik Mesin, Fakultas Teknik Universitas Pattimura
}

\begin{abstract}
Abstrak
Pemadaman listrik oleh PT.PLN (Persero) yang sering terjadi di beberapa wilayah di Indonesia khususnya pulau pulau terpencil, memaksa sebagian pihak harus menggunakan genset sendiri demi menjaga kontinuitas energi listrik baik itu untuk kebutuhan rumah tangga, perkantoran, industri dan sebagainya. Tidak sedikit biaya yang harus dikeluarkan pihak pengguna genset, hal ini sangat terasa khususnya bagi sektor industri, dimana ongkos produksi menjadi meningkat cukup signifikan.

Penelitian ini bertujuan untuk mengetahui kemungkinan penggunaan $d c$-ac converter sebagai alternatif pengganti genset untuk mensuplai beban listrik saat terjadi pemadaman listrik oleh PT.PLN (Persero) ditinjau dari aspek ekonomis dan teknis. Pengujian dilakukan pada golongan tarif/daya R-1/900 VA-RTM (Rumah Tangga Mampu) non subsidi.

Hasil penelitian menunjukkan bahwa, biaya operasional $d c-a c$ converter untuk continuous load maupun intermitten load lebih murah dibanding genset. Keuntungan penggunaan dc-ac converter ditinjau dari aspek teknis adalah noise kecil, vibrasi tidak ada dan penempatannya lebih fleksibel. Sistem $d c$-ac converter yang dilengkapi dengan sistem ac-dc converter (rectifier) dan pengoperasiannya secara otomatis menjadikannya sebuah sistem Uninterruptible Power Supply (UPS), sehingga alat ini praktis dan nyaman digunakan.
\end{abstract}

Kata kunci : Genset, dc/ac converter, rectifier, ATS, beban resistif.

\section{PENDAHULUAN}

Energi listrik sebagai sumber energi sekunder memiliki peran yang signifikan dalam setiap aktivitas yang ada di masyarakat. Setiap sektor baik itu sektor residential, commercial, public, maupun industry tidak bisa terlepas dari keberadaan energi listrik yang merupakan tenaga penggerak dalam setiap aktivitas (RUPTL, Wilayah Maluku dan Maluku Utara, 2008-2017). Namun demikian peran energi listrik tersebut sebagai tenaga penggerak dalam setiap aktivitas di beberapa daerah di Indonesia khususnya pulau pulau terpencil yang belum dilistriki tidak dirasakan oleh masyarakat. Pulau - pulau terpencil yang jumlah penduduknya sedikit dan tersebar dan kebutuhan listrik aktual relatif rendah, mengakibatkan investasi pengadaan pembangkit sulit untuk direalisasikan.

Adapun di beberapa pulau terpencil yang sudah dilistriki oleh pembangkit PT. PLN (Persero) dengan menggunakan PLTD, namun masalah suplai energi listrik secara kontinu masih sulit diwujudkan. Dimana pembangkit dioperasikan pada malam hari saja yang membuat sebagian masyarakat, sekolah dan perkantoran harus menggunakan genset pada pagi dan siang hari. Terbatasnya akses transportasi sehingga ketersediaan bahan bakar minim, perawatan dan perbaikan menjadi masalah yang sulit diatasi.

Pengadaan listrik di pulau - pulau terpencil dengan suplai energi listrik yang tidak kontinu, belum dapat menjawab masalah di berbagai sektor secara optimal. Kondisi seperti ini memaksa sebagian masyarakat, sekolah dan instansi pemerintah lainnya mengeluarkan sejumlah uang untuk investasi genset dan biaya operasional.

Kaitannya dengan uraian di atas, perlu dicari upaya untuk mengurangi beban masyarakat akan kebutuhan energi listrik. Artikel ini menyajikan pembahasan tentang kemungkinan penggunaan $d c-a c$ converter sebagai alternatif pengganti genset untuk mensulai beban listrik saat 
terjadi pemadaman listrik oleh PT.PLN (Persero) ditinjau dari aspek ekonomis dan teknis. Sistem ini dilengkapi dengan rectifier, aki, inverter dan automatic tranfer switch (ATS).

\section{KAJIAN TEORI}

Peraturan Pemerintah nomor 70 tahun 2009

Peraturan Pemerintah nomor 70 tahun 2009 tentang Konservasi Energi, dimana konservasi energi nasional menjadi tanggung jawab pemerintah pusat, pemerintah daerah provinsi, pemerintah daerah kabupaten/kota, pengusaha dan masyarakat. Pemerintah pusat, pemerintah daerah provinsi, pemerintah daerah kabupaten/kota bertanggung jawab melakukan sosialisasi secara menyeluruh dan komprehensip untuk penggunaan teknologi yang menerapkan konservasi energi, mengalokasikan dana dalam rangka pelaksanaan program konservasi energi dan memberikan kemudahan dan/atau insentif dalam rangka pelaksanaan program konservasi energi. Tanggung jawab pengusaha melaksanakan konservasi energi dalam setiap tahap pelaksanaan usaha; dan menggunakan teknologi yang efisien energi; dan/atau menghasilkan produk dan/atau jasa yang hemat energi. Masyarakat bertanggung jawab mendukung dan melaksanakan program konservasi energi.

\section{$D C$-AC Converter (Inverter)}

Bilamana sebuah penyearah (rectifier) merupakan suatu alat yang mampu mengubah tegangan ac menjadi tegangan dc, maka $d c-a c$ converter (inverter) adalah sebaliknya yaitu suatu alat atau suatu rangkaian yang mampu mengubah tegangan dc menjadi tegangan ac. $D C-A C$ converter (inverter) yang dimaksud di sini bukanlah sebuah generator motor, yaitu merubah tegangan dc dengan mempergunakan sebuah motor arus searah yang menggerakkan generator ac. Yang dimaksud di sini adalah rangkaian inverter, yang mempergunakan thyristor sebagai elemen utama.

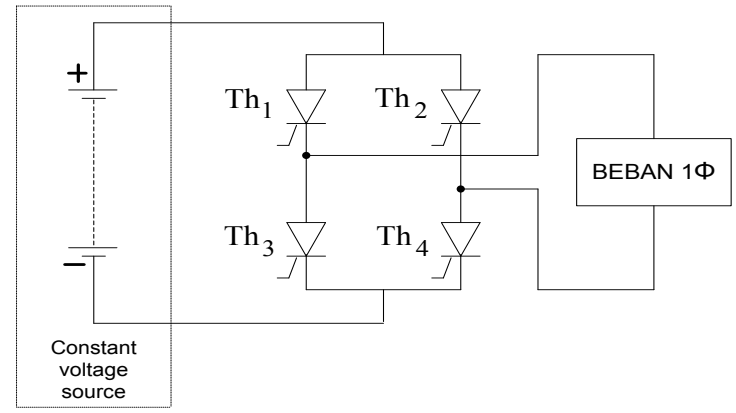

Gambar 1. Rangkaian Inverter Satu Fasa.

Sumber : Kadir, A (1986).

\section{Rectifier}

Rectifier adalah suatu alat atau rangkaian elektronika yang berfungsi mengubah tegangan bolak - balik (ac) menjadi tegangan searah (dc). Alat ini disebut juga sebagai power supply/catu daya yang digunakan untuk pengisian aki.

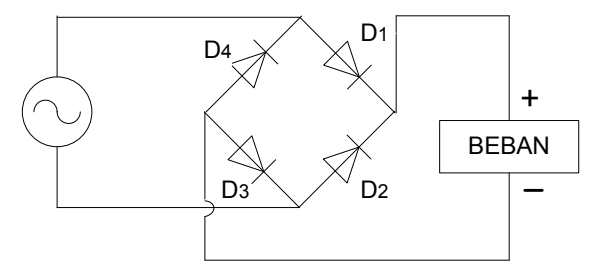

Gambar 2. Penyearah gelombang penuh.

Sumber : Zuhal (1991).

\section{Baterai Penyimpan (AKI)}

Menurut Neidle (1991), pada sel primer, listrik dibangkitkan oleh peristiwa kimia. Sel tersebut harus dibuang apabila bahan - bahan aktif habis. Hal ini sangat berbeda dengan baterai penyimpan (terdiri dari banyak sel sekunder), dimana bahan kimia pembentuknya dapat diaktifkan kembali dengan melewatkan arus dalam arah yang berlawanan dengan arah pengosongan muatan.

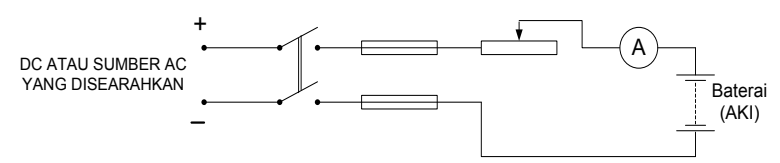

Gambar 3. Rangkaian dasar pengisian baterai. Sumber: Neidle (1991). 


\section{Clamp Multimeter}

Clamp Multimeter adalah alat untuk mengukur besaran listrik seperti daya listrik, tegangan listrik, arus listrik, tahanan, kapasitansi.

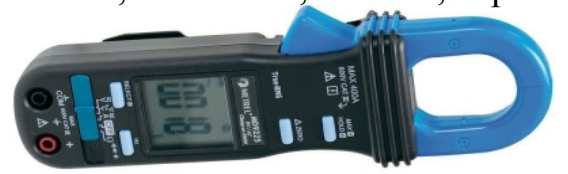

\section{Gambar 4. Clamp Multimeter.}

\section{Energi Listrik}

Energi listrik adalah hasil kali dari daya aktual dengan waktu. Secara matematis dapat dirumuskan sebagai berikut:

Energi Listrik $(\mathrm{KWH})=\mathrm{P} \times \mathrm{t}(\mathrm{KWH}) \quad$ atau

Energi Listrik $(\mathrm{KWH})=\mathrm{V} \times \mathrm{I} \times \mathrm{t}(\mathrm{KWH})$

Dimana :

$\mathrm{KWH}=$ Energi listri (Kilo watt jam)

$\mathrm{P} \quad=$ Daya peralatan listrik (Kilo watt)

$\mathrm{T} \quad=$ Waktu pemakaian peralatan listrik (jam)

$\mathrm{V}=$ Tegangan listrik (volt)

I $=$ Arus listrik (ampere)

\section{Tarif Listrik}

Tarif listrik pada asasnya tidak lain daripada suatu daftar harga dari perusahaan listrik untuk jasa - jasa yang diberikannya. Tujuan akhirnya adalah agar diperoleh penghasilan yang secukupnya guna menutupi semua biaya operasi dan mendapatkan suatu surplus atau laba yang wajar.

Tabel 1. Tarif Dasar Listrik Rumah Tangga R1

\section{Golongan Tarif/Daya Keterangan Tarif $(\mathbf{R p}$}

$/ \mathbf{k W h})$

$\begin{array}{lll}\text { R-1/450 VA } & \text { Subsidi } & 415 \\ \text { R-1/900 VA } & \text { Subsidi } & 586 \\ \begin{array}{l}\text { R-1/900 VA-RTM } \\ \text { (Rumah Tangga } \\ \text { Mampu) }\end{array} & \text { Non-Subsidi } & \mathbf{1 3 5 2} \\ \end{array}$

$\begin{array}{lll}\text { R-1/1300 VA } & \text { Non-Subsidi } & 1467,28 \\ \text { R-1/2200 VA } & \text { Non-Subsidi } & 1467,28\end{array}$

Sumber: PT. PLN (Persero)

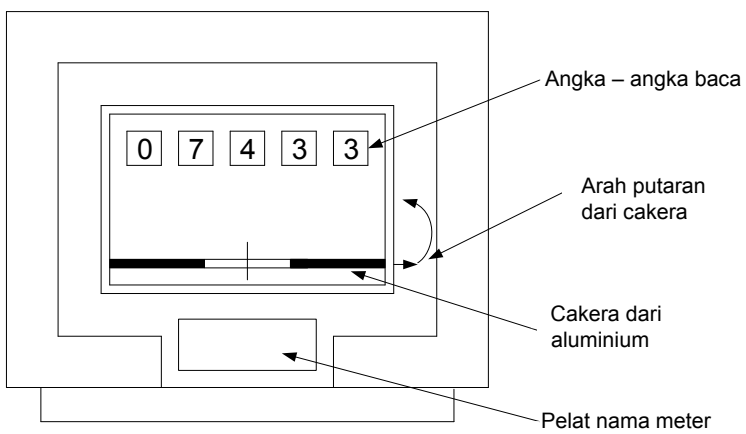

Gambar 5. KWH Meter.

Sumber : Suryatmo (1990)

Biaya Operasional Peralatan Listrik $=\mathrm{KWH}$ terpakai $\mathrm{x}$ harga per $\mathrm{KWH}$.

\section{METODE}

Penelitian ini bersifat eksperimen dengan mengoperasikan genset dan $d c / a c$ converter dengan daya yang sama yaitu masing - masing 1000 watt secara parsial untuk mensuplai beban listrik rumah tangga daya $900 \mathrm{VA}$ pada saat listrik padam. Hal ini bertujuan untuk membandingkan biaya operasional keduanya termasuk aspek teknis. Biaya operasional genset dihitung dari konsumsi bahan bakar premium, sedangkan biaya operasional $d c-a c$ converter dihitung dari biaya pemakaian listrik PLN saat pengisian aki.

Sistem operasional rectifier untuk pengisian aki dan sistem operasional $d c-a c$ converter untuk melayani beban listrik adalah secara otomatis dengan merancang sebuah alat automatic transfer switch (ATS).

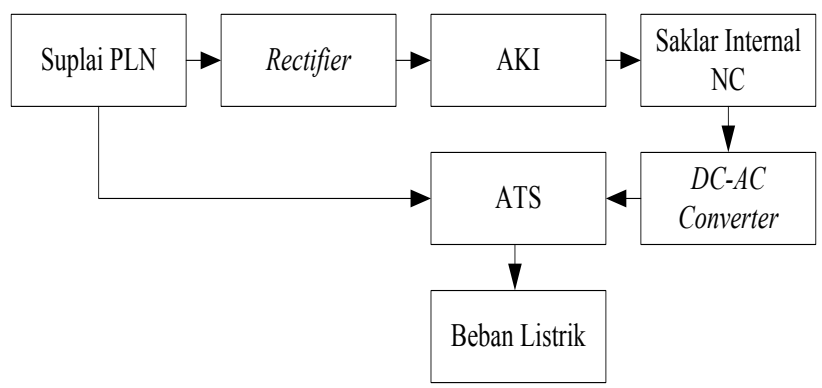

Gambar 6. Skema operasional $d c$-ac converter 
Gambar 6 di atas merupakan skema operasional $d c$-ac converter saat melayani beban listrik. Sistem ini dilengkapi dengan saklar internal NC dan automatic transfer switch (ATS). Pada saat aliran listrik dari PT. PLN (Persero) menyala, maka suplai PLN melayani beban listrik sekaligus rectifier melakukan pengisian aki. Sebaliknya, jika terjadi pemadan listrik dari PLN, maka beban listrik akan disuplai dari $d c-a c$ converter secara otomatis.

Adapun diagram alir penelitian ditunjukkan pada gambar 7 .

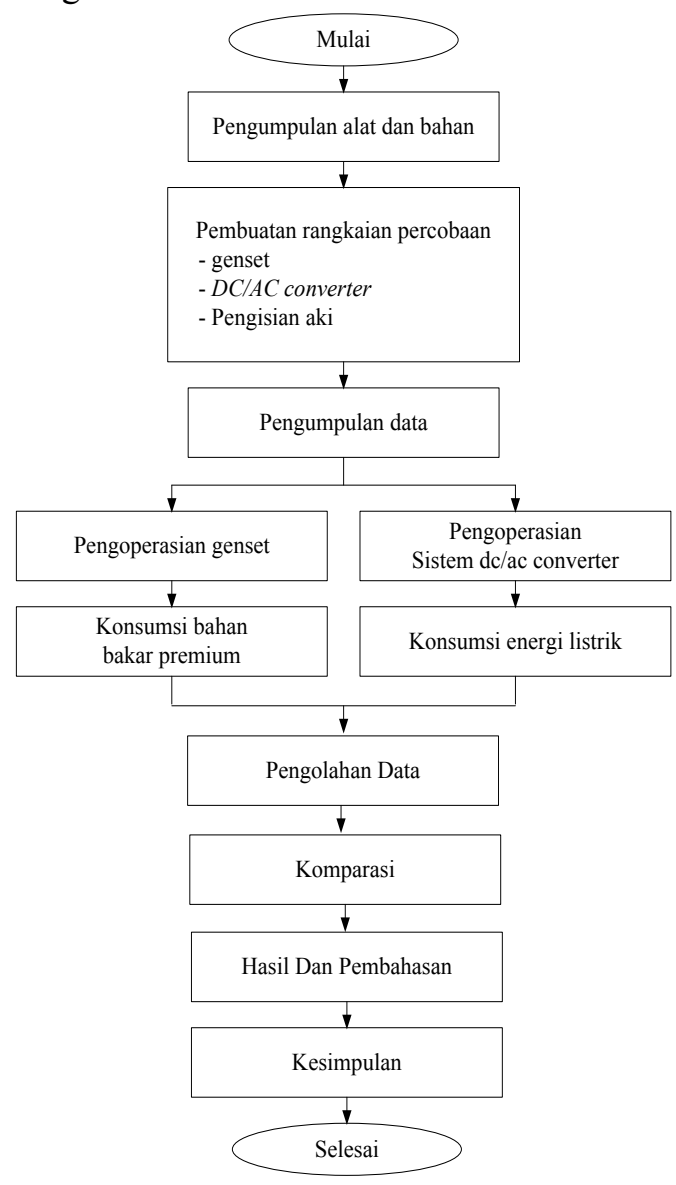

Gambar 7. Diagram alir penelitian.

\section{HASIL DAN PEMBAHASAN}

Beban listrik pada penelitian ini adalah beban resistif berupa lampu penerangan (lampu pijar). Adapun daya beban listrik bervariasi yaitu $100 \mathrm{~W}$, $200 \mathrm{~W}, 300 \mathrm{~W}, 400 \mathrm{~W}, 500 \mathrm{~W}, 600 \mathrm{~W}, 700 \mathrm{~W}$, $800 \mathrm{~W}$ dan $900 \mathrm{~W}$.

Tabel 2. menunjukkan rata - rata konsumsi bahan bakar premium (ml/jam) saat mengoperasikan genset untuk melayani beban listrik.

Tabel 2. Rata - rata konsumsi bahan bakar pada pengoperasian genset untuk beban resistif.

\begin{tabular}{|c|c|c|}
\hline No & $\begin{array}{c}\text { Daya Beban } \\
\text { Resistif (P) } \\
\text { (watt) }\end{array}$ & $\begin{array}{c}\text { Rata }- \text { Rata Konsumsi } \\
\text { Bahan Bakar }\left(\overline{\mathbf{F}_{\mathbf{c}}}\right) \\
(\mathbf{m l} / \mathbf{j a m})\end{array}$ \\
\hline 1 & 100 & 758,5 \\
\hline 2 & 200 & 779,5 \\
\hline 3 & 300 & $1.195,0$ \\
\hline 4 & 400 & $1.214,0$ \\
\hline 5 & 500 & $1.227,0$ \\
\hline 6 & 600 & $1.247,0$ \\
\hline 7 & 700 & $1.778,0$ \\
\hline 8 & 800 & $2.032,0$ \\
\hline 9 & 900 & $2.053,0$ \\
\hline \multicolumn{3}{|c|}{ Harga bahan bakar premiumadalah } \\
\hline
\end{tabular}
sebesar Rp.6.450,-/liter. Dengan demikian, biaya operasional genset adalah konsumsi bahan bakar premium $x$ Rp. 6.450,-. Adapun hasil perhitungannya di sajikan pada tabel 3 .

Tabel 3. Biaya operasional genset per jam untuk beban resistif.

\begin{tabular}{|c|c|c|}
\hline NO & $\begin{array}{c}\text { Daya Beban } \\
\text { Resistif (P) } \\
\text { (watt) }\end{array}$ & $\begin{array}{c}\text { Biaya Operasional } \\
\text { Genset } \\
\text { (Rp) }\end{array}$ \\
\hline 1 & 100 & 4.892 \\
\hline 2 & 200 & 5.028 \\
\hline 3 & 300 & 7.708 \\
\hline 4 & 400 & 7.830 \\
\hline 5 & 500 & 7.914 \\
\hline 6 & 600 & 8.043 \\
\hline 7 & 700 & 11.468 \\
\hline 8 & 800 & 13.106 \\
\hline 9 & 900 & 13.242 \\
\hline
\end{tabular}

Biaya operasional $d c-a c$ converter mengacu kepada konsumsi energi listrik pada saat rectifier melakukan pengisian aki 2 × 50Ah. Tarif listrik yang dijadikan acuan adalah R-1/900 VA-RTM 
(Rumah Tangga Mampu) non subsidi dengan harga Rp. 1.352,-/KWH.

Energi listrik terpakai dapat diketahui berdasarkan hasil pembacaan KWH meter dan hasil pengukuran nilai arus. Adapun hasil perhitungan biaya operasional $d c$-ac converter di sajikan pada tabel 4 dan tabel 5 .

Tabel 4. Biaya operasional $d c$-ac converter per jam untuk beban resistif berdasarkan hasil pembacaan KWH meter saat pengisian aki.

\begin{tabular}{|c|c|c|}
\hline $\begin{array}{c}\text { Daya } \\
\text { Beban } \\
\text { Listrik } \\
\text { (watt) }\end{array}$ & $\begin{array}{c}\text { KWH Terpakai } \\
\text { Hasil Pembacaan } \\
\text { KWH Meter } \\
\text { (KWH) }\end{array}$ & $\begin{array}{c}\text { Biaya } \\
\text { Operasional } \\
\text { DC-AC } \\
\text { Converter } \\
\text { (Rp) }\end{array}$ \\
\hline 100 & 0,1 & 135,2 \\
\hline 200 & 0,2 & 270,4 \\
\hline 300 & 0,3 & 405,6 \\
\hline 400 & 0,4 & 540,8 \\
\hline 500 & 0,5 & 676,0 \\
\hline 600 & 0,6 & 811,2 \\
\hline 700 & 0,7 & 946,4 \\
\hline 800 & 0,8 & $1.081,6$ \\
\hline 900 & 0,9 & $1.216,8$ \\
\hline
\end{tabular}

Tabel 5. Biaya operasional $d c$-ac converter per jam untuk beban resistif berdasarkan hasil pegukuran nilai arus saat pengisian aki.

\begin{tabular}{|c|c|c|}
\hline $\begin{array}{c}\text { Daya } \\
\text { Beban } \\
\text { Listrik } \\
\text { (watt) }\end{array}$ & $\begin{array}{c}\text { KWH Terpakai } \\
\text { Hasil Pengukuran } \\
\text { Nilai Arus } \\
\text { (KWH) }\end{array}$ & $\begin{array}{c}\text { Biaya } \\
\text { Operasional } \\
\text { DC/AC } \\
\text { Converter } \\
\text { (Rp) }\end{array}$ \\
\hline 100 & 0.086 & 116,3 \\
\hline 200 & 0.187 & 252,8 \\
\hline 300 & 0.288 & 389,4 \\
\hline 400 & 0.385 & 520,5 \\
\hline 500 & 0.486 & 657,1 \\
\hline 600 & 0.590 & 797,7 \\
\hline 700 & 0.689 & 931,5 \\
\hline 800 & 0.788 & $1.065,4$ \\
\hline 900 & 0.880 & $1.189,8$ \\
\hline
\end{tabular}

Gambar 8. menunjukkan perbandingan biaya operasional $d c-a c$ converter dengan genset saat melayani beban listrik secara kontinu (continuous load)

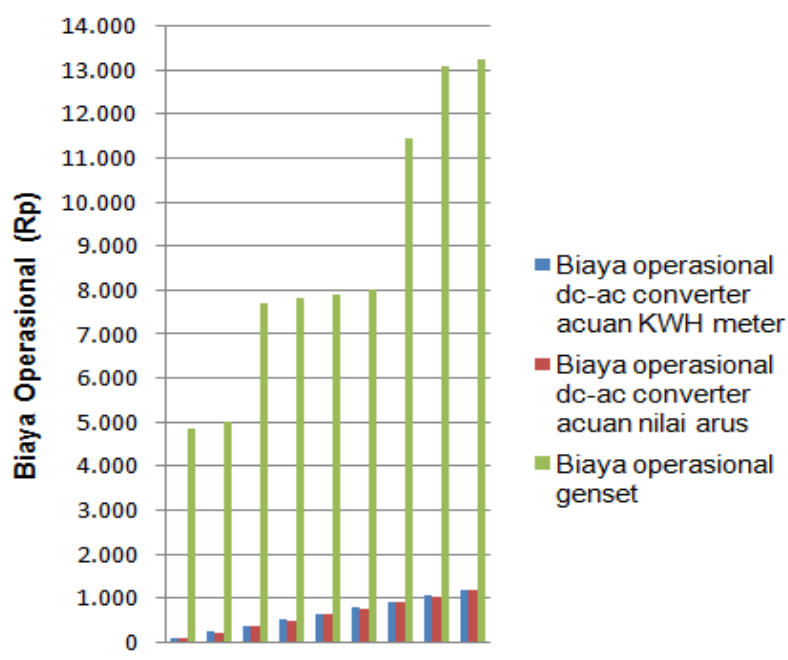

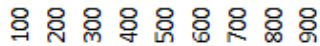

Daya Beban Listrik (watt)

\section{Gambar 8. Grafik Biaya Operasional DC-AC Converter Dan Genset}

Dari grafik tersebut dapat dilihat bahwa biaya operasional $d c-a c$ converter berdasarkan pengukuran nilai arus dan biaya operasional berdasarkan hasil pembacaan KWH meter terdapat perbedaan (koreksi), namun perbedaan tersebut tidak begitu besar..

Menurut Sapiie (1976), terjadinya nilai koreksi adalah diakibatkan oleh tahanan dalam dari alat ukur, dimana alat ukur itu sendiri menggunakan daya listrik.

Adapun nilai koreksi yang terjadi adalah sebagai berikut: pada beban 100 watt nilai koreksi sebesar 16,3\%, pada beban 200 watt nilai koreksi sebesar $6,95 \%$, pada beban 300 watt nilai koreksi sebesar $4,17 \%$, pada beban 400 watt nilai koreksi sebesar 3,89\%, pada beban 500 watt nilai koreksi sebesar 2,88\%, pada beban 600 watt nilai koreksi sebesar 1,69\%, pada beban 700 watt nilai koreksi sebesar 1,60\%, pada beban 800 watt nilai koreksi sebesar $1,52 \%$, dan pada beban 900 watt nilai koreksi sebesar $2,27 \%$. 
Grafik pada gambar 8 juga menunjukkan bahwa terdapat perbedaan yang sangat signifikan antara biaya operasional $d c$-ac converter dengan biaya operasional genset, dimana biaya operasional sistem dc/ac converter jauh lebih murah dibanding genset yaitu rata - rata $1: 16$.

Khusus untuk intermitten load, pengoperasian $d c-a c$ converter jauh lebih menguntungkan dibanding genset. Hal ini disebabkan biaya operasional genset saat melayani beban pada kondisi continuous load maupun intermitten load adalah relatif sama, sedangkan $d c-a c$ converter sesuai dengan kebutuhan listrik aktual.

Ditinjau dari aspek teknis, terdapat beberapa perbedaan yang signifikan antara penggunaan $d c$ ac converter dengan genset yang ditunjukkan pada tabel 6 .

Tabel 6. Komparasi sistem $d c-a c$ converter dengan genset ditinjau dari aspek teknis.

\begin{tabular}{|l|l|}
\hline \multicolumn{1}{|c|}{ Genset } & DC-AC Converter \\
\hline • Noise besar & • Noise kecil \\
- Vibrasi besar & - Vibrasi tidak ada \\
- Manual (dengan & - Otomatis (tanpa \\
operator) & operator) \\
- Penempatannya di & - Penempatannya \\
luar rumah & fleksibel \\
- Kurang nyaman & - Nyaman \\
- Menimbulkan polusi & - Tidak menimbulkan \\
suara & polusi suara \\
- Dapat dioperasikan & - Tidak dapat \\
sekalipun listrik PLN & dioperasikan apabila \\
padam dalam waktu & listrik PLN padam \\
yang cukup lama. & dalam waktu yang \\
& cukup lama, karena \\
& sangat tergantung \\
& kepada akumulator \\
& yang tersedia. \\
\hline
\end{tabular}

\section{KESIMPULAN}

Dari penelitian yang telah dilakukan dapat disimpulkan bahwa:

1. Biaya operasional $d c-a c$ converter untuk continuous load maupun intermitten load lebih murah dibanding genset.

2. Keuntungan $d c-a c$ converter ditinjau dari aspek teknis adalah noise kecil, vibrasi tidak ada dan penempatannya lebih fleksibel.

3. Sistem $d c-a c$ converter yang dilengkapi dengan sistem $a c-d c$ converter dan pengoperasiannya secara otomatis, menjadikannya sebuah sistem Uninterruptible Power Supply (UPS), sehingga alat ini praktis dan nyaman digunakan.

\section{DAFTAR PUSTAKA}

Kadir, A. 1986. Mesin Tak Serempak. Cetakan kedua. Djambatan. Jakarta.

Lander, C.W. 1987. Power Electronics, 2nd ed. McGraw-Hill Book Company (UK). Limited. New York.

Mohan. 1989. Power Electroniss: Converters, Applications and Design. John Wiley \& Sons, Inc. New York.

Neidle. 1991. Teknologi Instalasi Listrik. Erlangga. Jakarta.

Sapiie, S., dan O. Nishino. 1976. Pengukuran Dan Alat - Alat Ukur Listrik. cetakan kedua. Pradnya Paramita. Jakarta.

Zuhal. 1991. Dasar Teknik Tenaga Listrik Dan Elektronika Daya. Gramedia. Jakarta.

Peraturan-Pemerintah-No.-70-Tahun-2009tentang-Konservasi-Energi

http://listrik.org/pln/tarif-dasar-listrik-pln/[14 April 2018] 